\title{
UN MANUSCRITO OLVIDADO DE D. GREGORIO MAYANS Y SISCAR: «EL ABECÉ ESPAÑOL»
}

\author{
DOLORES AZORÍN \\ (Universidad de Alicante) \\ EMILIO FELIU \\ (Universidad de Alicante)
}

\section{Mayans y la Filologia; el problema ortográfico}

La figura de D. Gregorio Mayans y Siscar, justamente elogiada por Aritonio Tovar como «una de las más grandes entre las de la llustración española" (1981: 379), se inscribe por méritos propios entre la escasa nómina de españoles que, luchando muchas veces contra la incomprensión y la envidia de sus coetáneos, no cejaron en el intento de aproximar la ciencia y la cultura españolas a los avances que otros paises habian consolidado ya en este terreno. La incansable actividad que, a lo largo de su dilatada vida, llevó a cabo el erudito valenciano no sólo en el campo de la jurisprudencia - su especialidad universitaria-, sino también en el de la Historia crítica, humanidades latinas, recuperación de los clásicos castellanos, etc., es buena prueba de ello.

La contribución de Mayans a la Filología española del setecientos se enmarca dentro de un vasto programa de reformas que aparece, sistemáticamente expuesto, en la "Dedicatoria" a D. José Patiño que abre el primer volumen de sus Cartas morales, militares, civiles y literarias (Mayans, 1734a). La importancia de este texto - ya intuida por el propio autor

* Una versión resumida de este trabajo fue presentada por los mismos autores al XV Simposio de la Sociedad Española de Lingüística, celebrado en Córdoba, dias 16 al 20 de diciembre de 1985. 
que lo publica exento, meses después, con el título de Pensamientos literarios (Mayans, 1734c) - ha sido recientemente destacada por $\mathrm{A}$. Mestre (1981:57), quien lo considera «el primer programa de reforma solicitado por los jlustrados». En él, dejando a un lado los aspectos puramente autobiográficos ${ }^{1}$, Mayans plantea al poderoso ministro las tareas que deben acometerse para mejorar el lamentable estado cultural de la nación, tareas que incumben tanto a la racionalización de la enseñanza, como a la planificación de toda una serie de investigaciones, en distintos campos del saber que requieren, a su juicio, una inmediata ejecución. De la extensa lista de «empresas culturales»propuestas, destaca Mestre (1981: 58) «...un Diccionario de voces españolas anticuadas, Diccionario español-latino y latino-español, Diccionario de artes y ciencias (...) Colección de las mejores poesias españolas...", y un largo etcétera que ahorramos en aras de la brevedad.

Pero, por lo que hace a nuestro propósito, lo más destacable de la "Carta dedicatoria" a Patiño es el orden de prioridades que el autor impone en su ambicioso proyecto: el primer objetivo de la reforma lo constituye la lengua española. Consecuentemente con lo expresado en trabajos anteriores (Mayans, 1725;1727), reclama para el castellano la dignidad que le corresponde frente al latín, siendo el primero entre sus coetáneos en seguir las directrices que marcara el maestro Nebrija en la defensa de la lengua española y en los esfuerzos por dotarla de los instrumentos necesarios para su correcta codificación y posterior enseñanza. A este propósito, señala Lázaro Carreter (1949:158):

«D. Gregorio Mayans debe encabezar, por derecho propio, la historia de la empresa. Fue el primero en salir, desde el campo oratorio, en defensa de nuestro idioma. En modo alguno podía ser tildado de antihumanista o, sencillamente, de ignorante, el autor de voluminosos tratados latinos y de una gramática célebre, conocida en toda Europa por la pureza de su estilo en la lengua sabia. Sin embargo, desde joven había comprendido la maravillosa pujanza de los idiomas vulgares.”

La Carta a Patiño es sumamente explícita a este respecto. Entre las tareas prioritarias que deben acometerse están -y por este orden - la redac-

1 Sin que ello reste el mérito y la sinceridad que le corresponden, con la «Dedicatoria» a Patiño, pretendia D. Gregorio presentar ante el ministro una autodefensa de su labor investigadora con el fin de uavalar con este trabajo una solicitud que había hecho ante el gobierno. Habia quedado vacante el cargo de cronista de Indias por la muerte de Luis de Salazar y nuestro erudito había solicitado la plaza" (Mestre, 1981: 59). 
ción de una ortografía y una gramática españolas, que sienten las bases del empleo uniforme de nuestra lengua en sus distintas manifestaciones. En cuanto al proyecto de una gramática española, Mayans afirma tener reunidos los materiales suficientes para llevarlo a término; empresa que nunca realizó, quizás por no contar con el necesario respaldo oficial o porque otros se le adelantaron en el intento ${ }^{2}$. Su ortografía tampoco llegó a ver la letra impresa; pero, a diferencia de la gramática -mero proyecto a la sazón-, tenía ya redactado el borrador de su Abece Español, para cuya publicación solicita los auspicios del Ministro de Estado: «No he tratado con persona - afirma-, que aviendo visto y examinado mi Sistema, no le aya aprovado. Mucho más que eso importaria, que V.E. me mandasse que lo expusiesse Yo en la Censura universal. Porque assí lo espero, iré prosiguiendo mi proyecto" (Mayans, 1934: 16).

Fundamenta Mayans la defensa de su sistema en la necesidad de fijar la ortografía española a imitación no sólo de las lenguas clásicas, sino también de otras lenguas modernas, como el italiano y el francés, basándose - dice- "...en un solo principio, del qual procedan, como legítimas conseqüencias unas pocas Reglas, inteligibles de doctos, i indoctos, fácilmente practicables de grandes i chicos». (lbid.:14). Tal príncipio, aunque no lo explicite aquí, es el de la pronunciación; único criterio válido - como en adelante veremos - para simplificar la escritura, restituyendo a las letras la función a la que fueron destinadas, esto es, la de representar aquellos sonidos simples de que se valen las lenguas para simbolizar el pensamiento. La intuición fonológica está presente en el Abece Español, como lo estuvo asímismo en los grandes reformadores de la ortografía española, en cuyas fuentes bebe Mayans. Ahora bien, el ejemplo de tantos intentos fallidos pone en guardia a nuestro erudito sobre el éxito de aquellas reformas que no respeten los usos firmemente asentados, por ser práctica general en nuestra tradición ortográfica. Consecuente con ello, afirma que ninguna de sus reglas es contraria al uso común y, en definitiva, su sistema "no es otra cosa, sino una sencilla interpretación del Abece Español, en la que sigo a los ortógrafos en sólo aquello en que todos se conformaron entre si (...) una colección de reglas nada contrarias al sentir, i Uso universal; i lo que es mas digno de admiracion, hijas todas de un solo principio, claro i evidente" (Ibid.:14-15).

Con anterioridad a la Carta a Patiño, Mayans había manifestado públicamente su interés por la cuestión ortográfica. En 1728, incluye en la

2 Como afirma Lázaro Carreter (1949: 177) «..Mayans, en su carta a Patiño, estaba dispuesto a redactar un tratado para el que habia reunido importantes materiales. Pero, a sus propósitos se le adelantó Martínez Gayoso, que, en 1734, publicó su Gramática de la lengua castel/ana». 
Ortografia de su gran amigo, el impresor valenciano Antonio Bordazar, una carta de alabanza - recogida después en sus Cartas Morales.donde expresa de manera contundente que los males de la ortografía española radican en que «..no ha avido uno siquiera —ortógrafo, se entiende - que se aya hecho cargo de que cada una de las elementales Pronunciaciones Españolas tiene su letra fija en el Abecé Español, y no en el Griego, ni Latino, ni en cualquier otro extraño" (Mayans, 1728:88). Dos años más tarde, en la "Censura» que escribe a la segunda edición de este mismo texto, no vacila en defender el principio de la pronunciación, seguido por Bordazar en su tratado ortográfico: «.absolutamente apruevo, que se tengan por Polos de la Orthografía la Potestad de las letras i la Pronunciación españolas» (Mayans, 1730:149).

En varias ocasiones se ha aludido al enfrentamiento protagonizado por Mayans y Feijóo (Cf. La Viñaza, 1893; Tamayo, 1941; Peset, 1957; Mestre, 1981; Tovar, 1981) a propósito de la Ortografía de Bordazar. El incidente, que generó una extensa polémica epistolar ${ }^{3}$, tiene su origen en la falsa atribución del texto del impresor valenciano a Mayans. El ilustrado benedictino se había hecho eco del tal rumor y en carta privada a su comunicante, D. José Pardo Figueroa, manifiesta su desprecio por la obra, contradiciendo los elogios que le tributara cuando pensaba que se debía a la pluma de Bordazar. Al hacerse públicas las opiniones de Feijóo a través de su oponente Mañer —autor de un Anti-Teatro y también de un tratado ortográfico-, Mayans envía una carta latina al benedictino conminándole a que se retracte públicamente, para lo cual le amenaza con sacar a luz ciertos defectos de su Teatro Crítico. La respuesta de Feijóo, con las oportunas disculpas, no se hizo de esperar; así como tampoco, la del erudito valenciano, aceptándolas ${ }^{4}$. El propio Mayans, en una larga misiva al Conde del Aguila fechada en 1750, relataria el desarrollo de este infortunado incidente que, en adelante, iba a trazar una barrera de desconfianza entre Feijóo y él ${ }^{5}$. Pero, dejando a un lado lo anecdótico del suceso, lo cierto es que Mayans intervino en el proceso de gestación de la Ortografía de Bordazar trazando, en cierto modo, las líneas maestras del sistema ortográfico de su amigo el impresor. En la carta al Conde del Aguila antes mencionada, Mayans relataba los hechos de la manera siguiente:

3 Dicha polémica es resumida cronológicamente por Tamayo en su artículo «Mayans y la Ortografia de Bordazar», R.F.E., XXV, (1941), pp. 205-224.

4 La extensa carta de Mayans al Conde del Aguila, viene reproducida integramente en el artículo de Tamayo (vid. supra), pp. 210-213.

5 Un pormenorizado análisis de ias relaciones que mantuvieron ambos ilustrados españoles puede hallarse en el capítulo "Feijó y Mayans", que V. Peset incluye en su obra Gregori Mayans i la cultura de la ll.lustració, Barcelona-Valencia, 1975, Curial-Tres i quatre, págs. 393-428. 
«Antonio Bordazar que fue mi Impressor me pidió le explicasse la razón de mi orthographia: le di gusto en una conversación, y como era hombre de gran juicio, fue a su casa, y puso por escrito lo que Yo le había dicho. Mostrómelo después y habiéndome parecido bien, me pidio licencia para imprimirlo. Le dixe que para egecutarlo mejor podia ver algunas orthographías, como la de Matheo Alemán, Gonzalo Correas, y otras pocas, que le presté, y disfrutó, valiéndose de ellas en tal qual opinión, que no se conformaba con mi sistema orthográphico.» (Tamayo, 1941:211)

La primera referencia de Mayans al manuscrito de su ortografía se encuentra en la respuesta que, en 1732, dirige a José Hipólito Valiente quien le había remitido su Alfabeto o nueba qoloqacion de las letras ${ }^{6}$, sometiéndolo a su dictamen. El juicio del erudito no puede ser más claro: el carácter revolucionario de la reforma de Valiente, que compara con los ilustres intentos de Alemán y Correas, hace impracticable su ortografía por no acomodarse al uso común. En consecuencia, recomienda distinguir el uso del abuso, respetando todo lo uniformemente extendido y practicado y desechando lo sujeto a controversia y los usos no generales:

"Guiado Yo de estos principios, en la interpretación que tengo manuscrita del Abece Español, he establecido veinte y seis Letras, necesarias cada una de ellas para cierta, determinada, i distinta pronunciación, i suficientes todas para cuantas pronunciaciones ai [...] conformándome con el Uso de todos.» (Mayans, 1732: 183-84).

El respeto al uso común, que aparentemente contradice el principio de la pronunciación, no es en Mayans mera concesión a lo establecido, sino consecuencia de su concepción convencionalista de las lenguas. Al no existir una relación natural, analógica, entre los signos y las ideas que representan, sólo el consentimiento o beneplácito común es el soporte que garantiza el funcionamiento de aquéllas en tanto que instrumentos de comunicación. La vieja teoría convencionalista que, como muestra Coseriu (1977: 13-61), arranca de Aristóteles y a través de Boecio, en un primer momento, recorre el pensamiento lingüístico occidental, hasta llegar a la moderna formulación de la arbitrariedad del signo de F. de Saussure, es asumida por Mayans y conjugada en su sistema ortográfico con el principio de

6 Vid. descripción en La Viñaza (1893: 677), quien transcribe también integramente la carta de Mayans. En 1732, Gabriel de Artabe en su Hipólito contra lpólito rechazaba los planteamientos de Valiente, presentando un nuevo sistema ortográfico (Cf. La Viñaza, Ibíd: $678)$. 
la pronunciación. Así, en el "Prefacio» a su edición de la Ortografía de Nebrija afirma:

"La costumbre de escrivir que tiene cada uno, no deve ser la regla de la buena Escritura; porque los signos instituidos por el beneplácito común como son las letras; no significan por la voluntad de este, o de otro particular, aunque sea el mayor hombre del mundo; sino por el consentimiento común.» (Mayans, 1735a: 288-89)

La edición de la Ortografía de Nebrija será su único trabajo impreso sobre materia ortográfica. En él, aparte del «Prefacio» antes citado y de una "Carta» dedicatoria a D. José Patiño (Mayans, 1735b), incluye al final unas Reflexiones en las que extracta lo que más por extenso tenía ya trabajado en su Abecé Español. Dado el carácter de apéndice de las Reflexiones (Mayans, 1735c), el autor se detiene exclusivamente en la interpretación de aquellas grafías que pudieran presentar alguna dificultad en su uso. Así, por ejemplo, de las cinco vocales del castellano sólo examinará la /i/, representada comúnmente por las grafías $i$ latina e y griega o pitagórica, rechazando este último uso puesto que, en su sistema, la y es utilizada exclusivamente para representar a la consonante palatal /y/. Concluye Mayans el apéndice a Nebrija con una propuesta de abecedario, idéntica a la contenida en el manuscrito de su Abecé Español.

En aquella época, nuestro erudito abriga todavía la esperanza de que su sistema ortográfico llegue a publicarse, y en la "Dedicatoria» a Patiño vuelve, como en 1734, a invocar el patronazgo del Ministro para tal fin: «..reservé aquellas noticias - afirma - para cuando quiera V.E. que llegue el caso que Yo publique mi Abece Español, obra que tengo trabajada años ha" (Mayans, 1735b: 306). Pero, a pesar de sus anhelos y esfuerzos, no conseguiría el respaldo oficial, necesario para imprimir y difundir una obra de carácter normativo, como era ésta. Y, sobre todo, con la aparición de la Ortografía académica debió de dar definitivamente por perdida su pretendida reforma. En su correspondencia privada no ocultará, años más tarde, el desprecio que le merecían las reglas de la Academia; no obstante, no recomienda ya su sistema, sino el del maestro Nebrija. Así, en carta a Burriel, fechada en Oliva en 1745, dirá:

"Yo estoy persuadido a que son impracticables las reglas que ha intentado la Academia (...) observo que toda la mejoría que ai en la ortografía en doscientos i cinquenta años a esta parte se deve a los principios de Antonio de Nebrija» (Mestre, 1972: 70-71)

Todavía en 1759 escribe al Padre Galiana, respondiendo a la pregunta 
de éste sobre qué ortografía debe seguir en sus escritos, recomendándole que:

«En quanto a Orthografía Castellana, la mejor, absolutamente buena, i que no tiene excepción alguna en todas las Reglas, porque es totalmente uniforme en la práctica, acomodada a la pronunciación (sea esta la que fuere) es la del Maestro Antonio de Nebrija." (Castañeda, 1923: 169-70)

\section{El manuscrito mayansiano}

El interés de Mayans por la cuestión ortográfica está -como vemospresente desde muy temprano en sus escritos tanto públicos como privados, en los que aparecen frecuentes referencias a su “Abecé Español», todavia inédito y que forma parte de un manuscrito, escrito en cuartos, conservado entre los fondos mayansianos del antiguo Colegio del Corpus Christi de Valencia. En dicho manuscrito se distinguen, al menos aparentemente, tres textos diferentes ${ }^{7}$, para cuya completa identificación se hará necesario tomar en consideración las distintas alusiones que el propio Mayans hace, en múltiples ocasiones, a sus trabajos ortográficos, y muy especialmente a su Abecé.

El primer texto, que aparece intitulado bajo el epígrafe "El Abecé Español. Su intérprete D. Gregorio Mayans i Siscarn, tiene una extensión de 89 cuartos, y está plagado de en ocasiones amplísimas anotaciones marginales, que no son, en su mayor parte, sino addendas a la redacción inicial. A partir de la página 79 se abandona la materia propiamente ortográfica para pasar a exponer una serie de consejos relativos al "adorno" y la escritura, así como al uso de las distinciones. Dice el autor, al introducir este apartado:

«Aqui queria Yo dejar la pluma, quando me vino al pensamiento, que aviendo Yo interpretado el Abece de tal modo, que para el cumplimiento de una perfecta ortografia, solo me quedava tratar de el adorno, i como ultima mano de la escritura [...] Consideracion que me obligo a tomar tinta nuevamente... ».

7 Los identificamos como Texto 1, Texto 2 y Texto 3. Las referencias a los dos primeros se hacen mediante las llamadas $(A B C$, texto 1) y $(A B C$, texto 2), respectivamente. Dado que, en nuestra opinión, el tercer texto no pertenece aEl Abece Español, nos referimos a él como (ms., texto 3). La paginación que indicamos es la de cada uno de los textos considerado independientemente de los otros dos. 
Bien pudiera interpretarse esta afirmación como un mero recurso literario, bien como nota introductoria de un añadido que no apareciera en el texto original. Tomando en cuenta una de las referencias a esta obra que encontramos entre otros escritos de Mayans (quizá la más difundida), deberíamos al menos considerar esta segunda posibilidad. En efecto, declara D. Gregorio en carta a José Patiño (Mayans, 1734a):

«Tengo escrita esta Obra de manera que las Proposiciones que sirven de Texto, i que digo ser de todos, i por esso innegables, se pueden leer en medio quarto de hora, i estan acomodadas a la capacidad de los niños, por proximos que esten a la misma infancia, i la explicacion de dichas proposiciones, que forman un librito de veinte pliegos, es pueva i demostracion de la referidas Reglas".

La referencia a los veinte pliegos del tal librito no tiene por qué ser en absoluto exacta, y podría muy bien corresponderse con los veintitrés que en realidad ocupa este primer texto. Pero si tenemos en cuenta que los 3 últimos pliegos contienen esas cuestiones no estrictamente ortográficas, introducidas aparentemente a posteriori, la afirmación de haberse visto obligado a «tomar tinta nuevamente», puede no ser una mera licencia o un tópico, sino ajustarse totalmente a la realidad de los hechos.

Tras este primer texto aparece en el manuscrito otro, a todas luces incompleto, en el que se repiten aigunos de los contenidos de aquél, si bien expuestos con una brevedad extrema y con una absoluta claridad. Su misma distribución es síntoma inequívoco de la intención del autor, que no es otra que la de escribir «un apuntamiento de mi sentir, mui ligero peso a las manos... ( $A B C$, Texto 2:2). Consiste en una descripción ordenada del uso de cada una de las letras del Abecé, encabezado en cada caso por un epigrafe que anuncia de cuál de ellas se va a tratar a continuación. Como ya hemos señalado, este texto está incompleto, siendo lo último que en él aparece el epígrafe «De la $\mathrm{H}$ ». Estamos ante un opúsculo de marcado carácter didáctico, que muy bien pudiera corresponderse con las Proposiciones de que hablaba Mayans en la carta a Patiño citada en último lugar; aquéllas que, según él, se podían leer «en medio quarto de hora» y estaban acomodadas «a la capacidad de los niños». Y ésta es precisamente la imagen que a menudo se ha tenido de la ortografía mayansiense ${ }^{8}$, de la que se ha señalado como características más acusadas lo reducido de la extensión y el tono didáctico de la exposición. Por otra parte, confiesa Mayans al Ministro de Estado la intención de

8 Así aparece, por ejemplo, en la noticia que A. Esteve Serrano (1982) de «la ortografía no publicada de Mayáns i Sicar ", de la que como única referencia cita esta carta a don José Patiño. 
seguir en su proyecto si cuenta con el necesario respaldo, lo que pudiera explicar el carácter incompleto de este texto. Tal vez esperara, para terminarlo, a que se acercara el momento de la publicación; momento que no habría de llegar, con lo que quedó definitivamente inacabado. Tratándose de unas notas extraídas de la Interpretación del Abecé, ya concluida, no sería de extrañar que hubiese dejado para el último momento la culminación del proyecto, para el que no contaría finalmente con el apoyo necesario.

El tercer texto contenido en el manuscrito que nos ocupa no es, ni con mucho, tan extenso como la Interpretación (está escrito en tan sólo 16 cuartos), aunque resulta más próximo a ella que a las Reglas. Pudiera muy bien tratarse de una versión diferente, mucho más simplificada, de aquéIla, si bien la finalidad perseguida parece muy distinta, tanto por su extensión como por la profundidad en el tratamiento de las cuestiones y por el mismo tono. Parece, pues, tratarse de otro escrito, que no se ajusta en absoluto al "plan de la Obra" a que se refiere Mayans, conformado únicamente por las Reglas o Proposiciones y por la Interpretación del Abecé, como ya hemos visto.

En la «Carta al Lector que desea scrivir bien" (Mayans, 1735a), que sirve de Prefacio a su edición de la Ortografía de Nebrija, confiesa Mayans:

«Tuve animo de añadir unas Notas, i empece a hacerlas; pero me parecio que avia tanto que decir, que era empeñarme en escrivir un Libro muchas veces mayor que el de Lebrija, i anticiparme a decir lo que tengo escrito muy a la larga en mi Abecé Español, que publicaré, si estas Reglas se reciben bien".

Declara, así, haber empezado a elaborar unas Notas que no llega a incluir en su edición de las Reglas nebrisenses, por se materia más propia de un libro, que, por otra parte, ya tendría escrito. Pues bien, en el texto manuscrito que estamos ahora considerando interrumpe (casi al final) el hilo de la exposición con la siguiente exclamación:

«Mas adonde voi? Que hago Yo en pasar de Carta a Libro? » (Ms., Texto 3: 16)

Parece claro que lo que pretende en este caso es elaborar una pequeña doctrina que pudiera aparecer como Carta; es decir, a modo de prólogo o dedicatoria, como era frecuente en la época. Y efectivamente, aunque está tachado con posterioridad, puede leerse en el manuscrito: 
"Pero por quanto en esto tambien veo a muchos errores, $V$. Ex. me permitirá, que brevemente indique lo que se deve practicar».

La existencia de este destinatario interno explícito ( $V$. Ex.) viene a corroborar la hipótesis establecida. $Y$ tal vez pudiera identificarse esta 'carta demasiado extensa' con aquellas anunciadas Notas que suponian «empeñarse en escribir un libro».

En consecuencia, y según lo visto, tenemos que, de los tres textos de que se compone el manuscrito en cuestión, los dos primeros parecen corresponderse con el tantas veces mencionado por el propio Mayans Abecé Español, de acuerdo con las noticias que nos proporciona indirectamente acerca del «plan de la Obra». Y respecto del último texto nos atreveríamos a decir que se trata de una Carta destinada a servir de prólogo o Anotaciones a alguna obra de ortografía; carta que no llegaría a incluir en la realización definitiva de ese inicial proyecto, en parte por su extensión, en parte por dejar para mejor ocasión (la de la tan deseada publicación de su propia Ortografia) la exposición de sus ideas en esta materia.

Así pues, habría escrito Mayans, aparte las Cartas publicadas (dedicatorias o prefacios), tres obras de temática estrictamente ortográfica:

a) las Reflexiones a las «Reglas de Ortografía», de Antonio de Nebrija (1735c);

b) el Abecé Español, no publicado a pesar de su manifiesto interés, compuesto por unas «Reglas» (el inconcluso texto 2 del manuscrito) y una «interpretación» (texto 1); y

c) una Carta (texto 3), que permanece también, aunque por distintos motivos, inédita.

Para el establecimiento de la posible datación del Abecé, podemos valernos, también, de algunas de las alusiones al mismo hechas por su autor. Es, indudablemente, anterior a la publicación de los Origenes de la lengua española, del año 1737, y a la de la Ortografía de Nebrija, en la que hace mención expresa del mismo, como obra, no sólo terminada, sino en cierto modo ya antigua. En efecto, en la dedicatoria a Patiño (Mayans, 1735b) dice de su propia Ortografía:

«Obra que tengo trabajada años ha; pues ha mas de doce que la comunique manuscrita a mi estrechísimo amigo D. Francisco Joaquin Galiano Espuche...».

De considerar como cierta esta noticia, resultaría que el Abecé debió de 
ser compuesto hacia 1723, año en que gana Mayans la Cátedra de Código de Justiniano de la Universidad de Valencia. No habiéndonos sido posible acceder a carta alguna que pudiera haber acompañado a la remisión del manuscrito a su amigo, no nos es permitido, por el momento, negar absolutamente la realidad de la afirmación de Mayans. Lo que sí es cierto es que, de haber sido compuesto el Abece por aquellas fechas (hacia 1723), se trataría de una versión en parte al menos diferente de la que se conserva en la Biblioteca y Archivo Hispano Mayansiense; puesto que en el manuscrito al que hemos tenido acceso aparece reproducido literalmente $(A B C$, Texto 1:63) el parágrafo 29 del «Discurso Proemial de la Ortografía», aparecido en el tomo I del Diccionario de Autoridades:

«... me causan gran admiracion unas pocas palabras de la Real Academia, i son las siguientes: el reparo mayor es acerca de la $r$ como conjuncion; pero el uso comun lo tiene tan asentado, que en algunos Autores que han usado de la i latina en su lugar, ha sido notado como extravagancia...»?

En consecuencia, el Abecé Español, en su versión definitiva al menos, debió de escribirse con posterioridad a la publicación del Diccionario de Autoridades, cuyo tomo primero vio la luz en 1726. Por otra parte, como ya señaló en su día J. Gutiérrez Cuadrado (1981), la obra estaría ya redactada en 1732, según se desprende de la carta remitida por Mayans a D. José Hipólito Valiente, en enero de aquel año. Por tanto, la conclusión del Abecé, cuando menos en su versión definitiva, puede situarse con toda certeza entre 1726 y $1732^{10}$.

\section{El contenido de «El Abecé Español»}

El Abecé Español se compone, pues, de dos partes bien diferenciadas, aunque complementarias. La primera, que identificamos con el nombre de «nterpretación» ( $A B C$, Texto 1), es un extenso tratado teórico donde el autor examina detenidamente las distintas grafías que, para cada una de las indivisibles pronunciaciones españolas, se han venido utilizando en nuestra tradición ortográfica. Se trata, pues, de una revisión o interpretación crítica —como él mismo la llama—del abecedario español en la que

9 El texto en cursiva es transcripción exacta del parágrafo citado del «Discurso Proemial» (p. LVII).

10 De la posibilidad de fijar la datación de El Abecé Español en unos márgenes aígo más precisos, en atención a la cronologia relativa respecto de la Ortografia de Bordazar, trataremos en un ulterior trabajo. 
Mayans se sirve de sus conocimientos filológicos e históricos referidos a los orígenes de la lengua española y a los diferentes superestratos que, a través de la invasiones de otros pueblos y los distintos contactos culturales, intervinieron en la formación y desarrollo de la misma.

Comienza esta primera parte de Abece con un a modo de prólogo o advertencia al lector ( $A B C$, Texto 1: 1-3), donde se diagnostican las causas del lamentable estado de la ortografía española:

«Encontré que todas se reducen a dos. La una es que no se atiende a la naturaleza de las letras, ni a su combinación natural i primitiva. La otra es que no se distingue el uso universal de las letras del abuso de ellas.» ( $A B C$, Texto 1: 2)

A continuación, tras una breve exposición acerca de los orígenes del alfabeto y de su introducción en la península, Mayans concluye que el sistema más apropiado para la representación de la lengua española era el alfabeto latino, por ser «.. la Lengua Española hija legítima de la Lengua Latina" ( $A B C$, Texto 1:9). Ahora bien, todo abecedario debe ser completo, dicho en palabras del autor:

"Qualquier Abecedario (...) deve contener tantas letras, quantas sean bastantes para que representando cada una de ellas un sonido simple; juntas representen quantos sonidos ai en toda la lengua; i combinados entre si correspondan a quantas combinaciones de pronunciaciones pueda aver en adelante en dicha lengua.» ( $A B C$, Texto 1:9).

Supuesto este principio, conjetura Mayans que en la primitiva acomodación del alfabeto latino al idioma castellano se procedió de modo que, asignando una letra a cada sonido mínimo, se obtuviese «...La mayor conformidad entre la pronunciación i escritura. De tal manera que enterada la nación de los nombres i potestad de las letras, leyesse lo mismo que estuviesse escrito i no otra cosa: para lo qual sería necessario que no huviesse combinaciones ambiguas, sino invariables i fijas» ( $A B C$, Texto 1: 12).

Sin embargo, esta primitiva consonancia entre sonido y grafía que supone Mayans en el origen de la ortografía española, por distintas circunstancias, se fue paulatinamente deteriorando, hasta dar en el caos ortográfico que, manifiestamente, se observa en la actualidad.

La parte más voluminosa de la «Interpretación» (ABC, Texto 1: 13-50), 
la dedica el autor a esa revisión crítica, antes mencionada, de nuestra ortografía para concluir, finalmente, en el sistema o cartilla de las letras españolas, de la que ha eliminado todo lo superfluo - los «abusos» antes referidos-, restituyendo a cada grafía el valor o potestad que le corresponde. Para eilo, parte Mayans del número total de sonidos simples que tiene nuestra lengua; reconociendo la existencia de veinticinco, cinco corresponden a las vocales y los restantes a las pronunciaciones consonánticas. De cada sonido mínimo proporciona, además, una breve descripción articulatoria, la mayoría de las veces, acertada. La intuición fonológica de Mayans es, pues, evidente. Los veinte sonidos consonánticos que distingue son exactamente los que integran el sistema actual, con una sola excepción, diferencia $b$ de $v$. No reconoce, por tanto, como sonido simpie a la $h$, para él, mera nota de aspiración. En cuanto a la grafia $x$, dice de ella que es simple en la figura, pero compuesta en la pronunciación, equivalente en ella a -gs o-cs, introducida en nuestro sistema ortográfico por comodidad. Asímismo, considera a la $c h, \|, \tilde{n}, \mathrm{rr}$ como grafías que corresponden también a otros tantos sonidos simples propios del castellano y no como letras compuestas sin valor fonológico, como ocurre en otros tratados de la época ${ }^{11}$.

Tras estas consideraciones, presenta Mayans su sistema ortográfico, recogido en un cuadro en el que cada elemento viene definido atendiendo a su figura, nombre y expresión o potestad; tales elementos son veintiocho en total, pero advierte «. que la $\mathrm{H}$ no es letra, sino nota de respiración, i que la $\mathrm{K}$ es letra peregrina y superflua", con lo que la lengua española sólo tiene «...26 pronunciaciones -aquí incluye también a la $x-i$ yo añado que a ellas corresponden otras tantas letras" ( $A B C$, Texto 1:48).

Tras analizar minuciosamente la combinatoria de las letras y los pormenores de la silabación española, concluye Mayans esta primera parte de

11 Mayans no incurre en el error, común a otros reformadores de su época, de partir de las grafias o letras e irlas acomodando después según diversos principios. Su punto de partida es, por asi decirlo, el usistema fonológico" del español o conjunto de pronunciaciones elementales de la lengua, para pasar, seguidamente, a la adjudicación de una letra invariable a cada una de ellas. Supuesto este principio, y tras el reconocimiento de $/ \hat{\mathrm{c}} /, / \mathrm{J} / / \mathrm{J} / \mathrm{J} / \mathrm{f}$ como tales sonidos elementales, concluye que las grafías $c h, \|, \tilde{n}$ y $r r$ que los representan son, en efecto, dobles en la figura pero simples en la potestad o pronunciación. Véase, por el contrario, la teoria de Mañer (1730: 7 ) a propósito de las grafías $/ / / /$ y $u / v$ : «...y aunque se la pone a la $/ /$ diciendo que se forma puesta la punta de la lengua en el paladar, arrojando con fuerza el aliento para desprenderla, y rayendo un tanto el paladar con la punta de la misma, es visto que quasi es la propia pronunciación que la que a la / le tiene dado, añadiéndole sólo el esforzar un poco más el aliento, por lo que assi la $v$ como la // se reducen, la una a la vocal y la otra a su primera consonante" (el subrayado corresponde a la parte del texto de Mañer en que cita textualmente a A. Bordazar, según la edición de 1728 de su Ortografia). 
su Abecé con una defensa de los principios en que basa su reforma ortográfica, demostrando con distintos argumentos la inviabilidad de todo sistema fundado en la consideración del origen etimológico de las palabras. En primer lugar, porque el objeto de la escritura es muy otro: "...La escritura es un medio - dirá- para declararnos [...] i exprimir aqueilas voces que si hablassemos pronunciariamos. Pues si este fin se puede conseguir con la mayor facilidad del mundo [...] porque se ha de proponer un medio como es el conocimiento del origen" ( $A B C$, Texto 1: 56). En segundo lugar, porque el principio del origen obligaría a los usuarios de un sistema tal al conocimiento no sólo del latín, sino también de las otras lenguas matrices del castellano. $Y$ en tercer lugar, porque «.nadie sabe, ni puede saber todas las origines de la lengua española» ( $A B C$, Texto 1:57). Y esto último, nadie mejor que D. Gregorio lo podía afirmar, teniendo en cuenta que una de sus contribuciones más brillantes a la filología española son sus Origenes de la lengua española ${ }^{12}$ donde, aparte del núcleo fundamental latino, reconocia nuestro erudito la influencia ejercida por otras lenguas en la formación y evolución del español.

En la segunda parte del Abecé Españo/ proporciona Mayans, tras una breve introducción donde vuelve a insistir en la defensa del principio de la pronunciación, las reglas que deben observarse para el uso correcto de su sistema ortográfico. A tal efecto, señala: «..separaré lo cierto de lo incierto, $i$ únicamente propondré por regla, lo que todos saben, i universalmente estuviere admitido de todos" ( $A B C$, Texto 2: 2).

Procede, pues, letra por letra, siguiendo el orden del A-B-C-, partiendo siempre del sonido simple que representa cada una de ellas, especificando siempre su uso, posición en la sílaba, etc. Los artículos que dedica a las distintas grafías, suelen variar de extensión, dependiendo de la dificultad de empleo de las mismas.

Este texto, como hemos señalado antes, está inconcluso, truncándose en la descripción de la letra $h$, de la que sólo aparece el epígrafe.

\section{El afán sistematizador de Mayans}

Son muchas las ocasiones en que se refiere D. Gregorio Mayans a su SISTEMA ortográfico. Y en efecto, en el Abecé Español se insiste en la ne-

12 G. Mayans y Siscar, Origenes de la Lengua Española, Madrid, Juan de Zúñiga, 1737. Vid. También la reciente edición de A. Mestre en Obras Completas, II, 1984. 
cesidad de establecer unas reglas fijas que puedan servir siempre de guia al "escriviente». La regularidad es (o debe ser), en su opinión, la característica fundamental de la Ortografía Española, cuya "mayor perfeccion consiste en no tener excepcion alguna» (ABC, Texto 1:71).

En los textos 1 y 3 del manuscrito (aquéllos que hemos llamado, respectivamente, Interpretación y Anotaciones) expone el sistema que debería seguirse en la composición de una Cartilla. Sistema que debería contener necesariamente:

la presentación de todas las letras del Abece;

las vocales, "como elementos simplicissimos de la articulación humana";

las deletreaciones de las sílabas que hay y puede haber en la lengua española;

la distribución de los diptongos y triptongos;

y, a modo de ejemplificación, la deletreación de las principales oraciones «que deve saber el cristiano».

La deletreación de las sílabas vendría dispuesta por un «ingenio mathematico" (que no explicita), con lo que ocuparía "solo una hogita (Ms., Texto $3: 10)$.

Aunque el contemplar estos cinco apartados no supone novedad alguna importante respecto de otras ortografías de la época, si puede serlo la disposición y ordenación de los mismos, que comporta una concepción orgánica de la obra que, por otra parte, se pone de manifiesto a todo lo largo de la exposición.

Y si a lo ya dicho añadimos una clara tendencia a la clasificación, que alcanzará su máxima cota al establecer una muy completa tipologia estructural (valga el término) silábica, y una gran capacidad analítica, presente en toda la obra, resultará casi obvio señalar cuál es su mayor aportación. Debemos estar necesariamente de acuerdo con J. Siles (1984: XXIV) cuando, refiriéndose a los Orígenes de la lengua española, afirma:

«Esta voluntad de sistematización me parece — tanto o más que toda la cultura y conocimientos que demuestra-lo mejor del pensamiento mayansiano».

Pues bien, también el Abecé Españo/ tiene en esa decidida voluntad su mayor virtud. 


\section{Referencias bibliográficas}

Castañeda, V. (1923), «Cartas familiares y eruditas del Padre Luis Galiana a D. Gregorio Mayans y Siscar, con la respuesta de éste", Revista de Archivos Bibliotecas y Museos, LXXXIII, pp. 159-232.

Coseriu, E. (1977), «L'arbitraire du signe: sobre la historia tardía de un concepto aristotélicos en Tradición y novedad en la ciencia del lenguaje, Madrid, Gredos.

Esteve Serrano, A. (1982), Estudios de teoria ortográfica del español, Publicaciones del Departamento de Lingüistica General y Crítica Literaria. Universidad de Murcia.

Gutiérrez Cuadrado, J. (1981), «Mayans y la lengua de la ciencia» en Mayans y la llustración. Simposio Internacional en el bicentenario de la muerte de Gregorio Mayans. Publicaciones del Ayuntamiento de Oliva, Valencia, t. I, pp. 317-346.

Lázaro Carreter, F. (1949), Las ideas lingüisticas en España durante el S. XVIII, Madrid, C.S.I.C. Anejo XLVIII de Ia R.F.E.

Mañer, S. J. (1730), Methodo ilustrado de las más precisas Reglas de Reglas de Orthographia Española, Madrid, Antonio Marin.

Mayans, G. (1725), Oracion en alabanza de D. Diego Saavedra Fajardo, Valencia.

- (1727), Oración que exhorta a seguir la verdadera idea de la eloquencia española, Valencia.

- (1728) "Carta a Antonio Bordazar alabándole la Orthografia» en Cartas morales, militares, civiles y literarias, Madrid, 1734, Juan de Zúñiga. (Todas las referencias que, en adelante se hagan a las Cartas Morales, corresponden a la edición de Valencia, 1773, Salvador Fauli), pp. 85-92.

- (1730), «Carta o Censura a la Orthografía Española de A. Bordazar», en Cartas morales.., pp. 146-150.

- (1732), "Carta a José ipólito Valiente» en Cartas morales... pp. 181-184.

- (1734a), "Carta dedicatoria a D. José Patiño», en Cartas morales... pp. 13 y sigs.

- (1734b), Pensamientos literarios, Madrid.

- (1735a), "Carta o Prefacio del Libro intitulado Reg/as de Orthografía en la Lengua Castellana, compuestas por el Maestro Antonio de Nebrija” en Cartas morales..., pp. 281-292.

- (1735b), "Carta dedicatoria de D. Gregorio Mayans y Siscar dirigiendo el libro intitulado Reglas de Orthografía en la Lengua Castellana, compuestas por el Maestro Antonio de Lebrija al Exmo. Señor D. Josef Patiño", en Cartas morales..., pp. 192-312. 
- (1735c), «Refecciones de D. Gregorio Mayans y Siscar sobre las Reglas de Orthografía en la Lengua Castellana, compuestas por el Maestro Antonio de Lebrija", en A. de Lebrija, Reglas de Orthografía en la Lengua Castellana, ed. de G. Mayans, Madrid, Juan de Zúñiga, 1735, pp. 53-89.

Mestre, A. (ed. 1972), Epistolario II. Mayans y Burriel, Valencia, Publicaciones del Ayuntamiento de Oliva.

- (1981), Perfil biográfico de D. Gregorio Mayans y Siscar, Valencia, Publicaciones del Ayuntamiento de Oliva.

- (ed. 1984), Gregorio Mayans y Siscar. Obras Completas, t. II, Literatura, Valencia, Publicaciones del Ayuntamiento de Oliva.

Peset, V. (1975), Gregori Mayans i la cultura de la II/ustració, BarcelonaValencia, Curial-Tres i quatre.

Siles, J. (1984), "Los origenes de la Lengua Española de y en Gregorio Mayans", en A. Mestre (1984, ed.), G. Mayans y Siscar. Obras Completas, t. II. Literatura, pp. VII-XXVIII.

Tamayo, J. A. (1941), «Mayans y la Ortografía de Bordazar», R.F.E., XXV, pp. 205-224.

Tovar, A. (1981), "Mayans y la Filología en el S. XVIll» en Mayans y la llustración. Simposio Internacional en el bicentenario de la muerte de Gregorio Mayans y Siscar, Publicaciones del Ayuntamiento de Oliva, Valencia, t. I, pp. 379-408.

Viñaza, Conde de la (1893), Biblioteca Histórica de la Filología Castellana, t. $2^{\circ}$, Madrid, Imp. de Manuel Tello (ed. de Atlas, 1978). 